УДК 612.616.31:616-003.725

СКоллектив авторов

ЭКСПЕРИМЕНТАЛЬНОЕ ИССЛЕДОВАНИЕ ВЛИЯНИЯ РЕКОМБИНАНТНОГО ЛАКТОФЕРРИНА
ЧЕЛОВЕКА НА УРОВНИ АНДРОГЕНОВ И ОСНОВНЫЕ ПОКАЗАТЕЛИ ЛИПИДНОГО ОБМЕНА

\author{
Ю.А. Рудниченко*, В.С. Лукачевич, И.В. Залуцкий
}

Институт физиологии НАН Беларуси,

220072, Беларусь, Минск, ул. Академическая 28; эл. почта: link060619@list.ru

\begin{abstract}
Системное (в течение 2,5 месяцев) введение per os рекомбинантного лактоферрина человека per os вызывало повышение уровня общего тестостерона в сыворотке крови и гомогенатах семенников экспериментальных животных, которое коррелировало с увеличением свободного тестостерона. В сыворотке крови имело место увеличение концентрации субстратов стероидогенеза (холестерина, прогестерона и 17-ОН прогестерона) и снижение содержания эстрадиола, что приводило к увеличению тестостерон/эстрадиолового индекса в 3,6-3,8 раза. Изучены основные показатели липидного и белкового обмена. Полученные результаты свидетельствуют об активации лактоферрином синтеза андрогенов и липидного обмена.
\end{abstract}

Ключевые слова: тестостерон, стероидогенез, рекомбинантный лактоферрин человека, липидный и белковый обмен

DOI 10.18097/PBMC20166205566

\section{ВВЕДЕНИЕ}

Андрогены являются регуляторами широкого спектра физиологических реакций и процессов развития репродуктивной и других систем у мужчин. Правильная регуляция их продукции через гипоталамо-гипофизарно-гонадную ось необходима для развития мужского фенотипа, а также для инициации и поддержания сперматогенеза [1]. Действие андрогенов опосредовано андрогеновыми ядерными рецепторами, которые функционируют как лиганд-зависимый фактор транскрипции, регулирующий экспрессию множества андрогенчувствительных генов [2].

Основной половой гормон - тестостерон ещё в эмбриональном периоде начинает оказывать детерминирующее воздействие на формирование, а в дальнейшем и на функционирование половых органов и придаточных половых желез [3], сперматозоидов в семенных канальцах [4] и сексуального поведения [5] в зрелом возрасте. Помимо общеизвестной роли в регуляции половой функции, тестостерон обладает разносторонним стимулирующим действием на организм: активирует анаболические реакции, выражающиеся, в частности, в наращивании мышечной массы и уменьшении висцерального жира; поддерживает нормальное функционирование центральных нейронов; увеличивает экспрессию ряда регуляторных белков $[6,7]$. Показано его влияние на клеточный и гуморальный ответ иммунной системы [8].

Семенники являются главным местом синтеза и секреции андрогенов, в том числе и тестостерона, который также может синтезироваться в небольших количествах яичниками у женщин и корой надпочечников у обоих полов [2]. У млекопитающих в онтогенезе существует как минимум два типа тестикулярных эндокриноцитов. Первый тип - это фетальные клетки Лейдига, возникающие и функционирующие пренатально в период маскулинизации урогенитальной системы самцов [9]. Образуясь в яичках зародыша, эти клетки уже на ранних этапах способны синтезировать тестостерон, который под действием $5 \alpha$-редуктазы (КФ 1.3.99.5) преобразуется в наиболее активную форму дигидротестостерон в некоторых эмбриональных репродуктивных тканях. Второй тип - взрослые клетки Лейдига, возникающие постнатально в период полового созревания. Они синтезируют тестостерон, который требуется для поддержания сперматогенеза и развития мужских вторичных половых признаков. Хотя тестикулярные эндокриноциты составляют только около 5\% от всех типов клеток в яичках, именно они образуют более 95\% циркулирующего тестостерона [10].

В фетальных и взрослых клетках Лейдига осуществляется биосинтез тестостерона при участии, по крайней мере, четырёх стероидогенных ферментов. Синтез главного мужского андрогена начинается с холестерина [11]. Первый стероидогенный фермент цитохром P450scc (цитохром Р450 холестерингидроксилаза/20,22-лиаза) находится на внутренней мембране митохондрий [12] и катализирует превращение холестерина в прегненолон, который диффундирует из митохондрий в окружающий гладкий эндоплазматический ретикулум, где находятся другие стероидогенные ферменты, в том числе $3 \beta$-гидроксистероиддегидрогеназа (КФ 1.1.1.145), цитохром $\mathrm{P} 450 \quad 17 \alpha$-гидроксилаза/17,20-лиаза (КФ 1.14.99.9) и 17ß-гидроксистероиддегидрогеназа (КФ 1.1.1.51) [13]. Эти ферменты осуществляют цепь последовательных преобразований: прегненолон $\rightarrow$ прогестерон $\rightarrow$ 17-ОН-прегестерон $\rightarrow$ андростендион $\rightarrow$ тестостерон. Необратимое превращение тестостерона в эстрадиол происходит под действием ароматазы 


\section{ВЛИЯНИЕ РЕКОМБИНАНТНОГО ЛАКТОФЕРРИНА ЧЕЛОВЕКА НА СТЕРОИДОГЕНЕЗ}

(КФ 1.14.14.14). Она содержится во многих тканях, особенно в печени и жировой клетчатке. У мужчин этим путём образуется 75\% эстрадиола, остальное количество вырабатывается непосредственно в яичках [14].

В рамках выполнения программы Союзного государства "БелРосТрансген-2" из молока трансгенных коз получен рекомбинантный лактоферрин человека (рчЛФ) $[15,16]$ - один из основных белковых компонентов молока, негемовый железосвязывающий гликопротеин, относимый к семейству трансферринов. В наших условиях белок был выделен из молока с помощью катионообменной хроматографии (до 95-98\% чистоты) и имел степень насыщения железом 10-20\% [17]. Его молекула представляет собой одну полипептидную цепь, с молекулярной массой приблизительно 80 кДа, в зависимости от степени гликозилирования молекулы (от 3\% до 11\%) [18].

В зависимости от степени обратимого связывания ионами $\mathrm{Fe}^{3+}$, ЛФ может существовать в трёх формах: свободной от $\mathrm{Fe}^{3+}$ (апо-ЛФ) и ассоциированной с одним (monoferric lactoferrin) или двумя ионами $\mathrm{Fe}^{3+}$ (холо-ЛФ), имея различные трёхмерные структуры [19]. Апо-ЛФ имеет открытую конформацию, холо-ЛФ является замкнутой молекулой с большей устойчивостью к протеолизу [20].

Благодаря своему широкому распространению в различных тканях и участию во многих физиологических процессах ЛФ можно отнести к полифункциональным белкам. Помимо регулирования всасывания железа он модулирует иммунные реакции, обладает антибактериальной активностью, опухолемоделирующими и противовоспалительными свойствами, участвует в регуляции роста и дифференцировки клеток и др. [21, 22].

Ранее нами было показано, что при длительном потреблении рчЛФ не наблюдается изменений сывороточной концентрации гонадотропинов лютеинизирующего и фолликулостимулирующего гормонов, контролирующих синтез тестостерона в клетках Лейдига по принципу обратной связи [23]. Однако эти результаты не исключают возможности изменения синтеза и/или секреции тестостерона, обусловленного участием рчЛФ в регуляции активности или синтеза специфических ферментов стероидогенеза.

Целью настоящего исследования явилось изучение воздействия рчЛФ на уровень тестостерона и его предшественников в стероидогенезе крыс, a также основных показателей липидного и белкового обмена для раскрытия возможных регуляторных механизмов.

\section{МЕТОДИКА}

Исследования проведены на белых половозрелых крысах-самцах $(\mathrm{n}=70)$ в возрасте 2-х месяцев, массой 250-290 г., которых содержали в стационарных условиях вивария. Все особи находились на одинаковом рационе, имели свободный доступ к воде и пище, условия их содержания соответствовали общепринятым нормам обращения с лабораторными животными.

Согласно задачам эксперимента, животные были разделены на четыре группы (n=17-18). Первая группа (контрольная) содержалась на стандартном рационе и получала ежедневно изотонический раствор $\mathrm{NaCl}$ в объёме 0,1 мл. Особей второй, третьей и четвёртой групп кормили стандартным рационом, с ежедневным добавлением per os рчЛФ в дозах 20, 100 и 200 мг/кГ в объёме 0,1 мл в течение 2,5 месяцев.

Животных, лишённых утреннего кормления, выводили из эксперимента декапитацией под эфирным наркозом, получали сыворотку крови и отбирали ткани семенников. Содержание общего и свободного тестостерона, эстрадиола, прогестерона и $17-\mathrm{OH}$ прогестерона определяли методом иммуноферментного анализа с использованием диагностических наборов фирмы “Хема" (РФ), а уровень общего холестерина, триглицеридов, холестерина липопротеинов высокой и низкой плотности (ХС ЛПВП и ХС ЛПНП), общего белка - с помощью наборов “Анализ X” (Беларусь), содержание альбумина - с применением набора RANDOX (Великобритания). Отношение тестостерон/эстрадиол в сыворотке крови крыс устанавливали расчётным путём.

Семенники помещали в $0,01 \mathrm{M} \mathrm{K,Na-фосфатный}$ буфер $(\mathrm{pH} \mathrm{7,4)} \mathrm{с} \mathrm{1,15 \%} \mathrm{KCl}$ в соотношении 1:10 (вес/объём), гомогенизировали и центрифугировали при $12000 \mathrm{~g}$ в течение 20 мин (при $4^{\circ} \mathrm{C}$ ) [24], используя в дальнейшей работе надосадочную жидкость.

Экспериментальные данные обработаны с помощью MS Excel, Origin 6.1 и представлены в виде медианы (Ме) и интерквартильного размаха (25-й процентиль - 75 процентиль) - (25\%; 75\%). Нормальность распределения показателей проверяли при помощи теста Шапиро-Уилка. Для сравнения групп по одному признаку применяли U-критерий Манна-Уитни для независимых выборок с использованием пакета программ Statistica 6.0. Достоверным считали уровень значимости $\mathrm{p} \leq 0,05$.

\section{РЕЗУЛЬТАТЫ И ОБСУЖДЕНИЕ}

В ходе проведенных исследований установлено, что уровень общего тестостерона в сыворотке крови крыс достоверно возрастал на 137,5\%, 200\% и 125\% при пероральном введении рчЛФ в дозах 20, 100 и 200 мг/кг соответственно (рисунок, А). Аналогичные изменения происходили и с содержанием свободного тестостерона - на 70,9\%, 128,8\% и $139,1 \%$ соответственно, что может указывать на возрастающую долю именно биологически активного андрогена (рисунок, Б), а соотношение тестостерон/эстрадиол достоверно возрастало в 3,2, 3,6 и 3,8 раз (рисунок, В).

При действии рчЛФ в дозе 200 мг/кг отмечено повышение уровня предшественников тестостерона (прогестерона и 17-ОН прогестерона) на 20\% и 52,1\% соответственно. В этих условиях содержание 

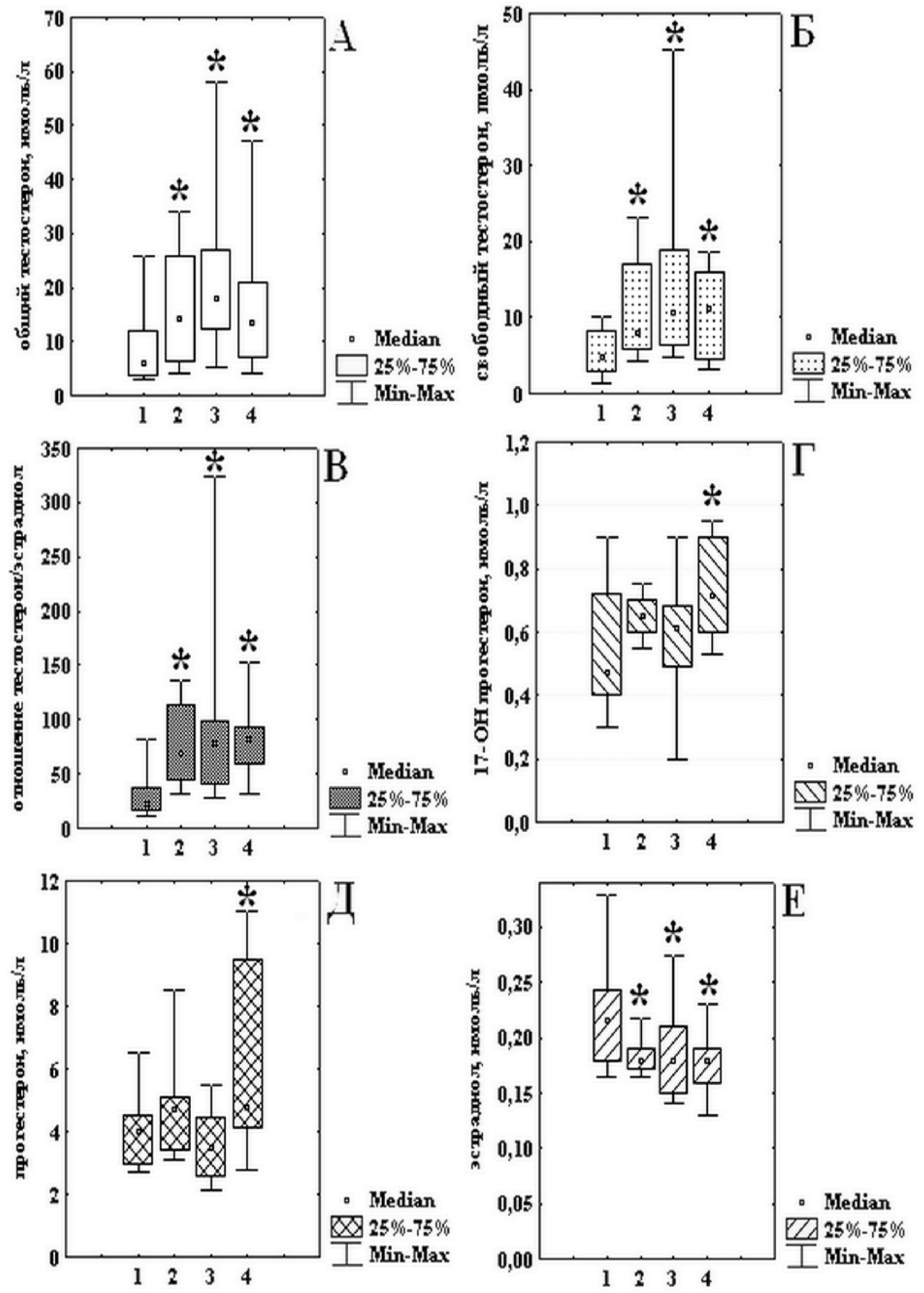

Рисунок. Содержание общего, свободного тестостерона и его предшественников в стероидогенезе в сыворотке крови крыс после 2,5 месяцев перорального введения рекомбинантного лактоферрина человека. * - достоверные отличия от контрольной группы $(\mathrm{p}<0,05),(\mathrm{Me} ; 25 \%-75 \%) .1$ - контрольная группа, 2 - группа, получавшая рчЛФ per os в дозе 20 мг/кг, 3 - группа, получавшая рчЛФ per os в дозе 100 мг/кг, 4 - группа, получавшая рчЛФ per os в дозе 200 мг/кг. 


\section{ВЛИЯНИЕ РЕКОМБИНАНТНОГО ЛАКТОФЕРРИНА ЧЕЛОВЕКА НА СТЕРОИДОГЕНЕЗ}

эстрадиола в сыворотке крови крыс достоверно снижалось во 2-4 группах на $16,7 \%, 16,7 \%$ и $16,5 \%$ соответственно, что, возможно, связано со снижением активности или синтеза ароматазы, которая участвует в превращении тестостерона в эстрадиол (рисунок, Е).

Содержание общего тестостерона в надосадочной жидкости гомогената тканеи семенников крыс было значимо увеличено при минимальной изучаемой дозе перорального потребления рчЛФ - уровень данного андрогена статистически значимо возрастал на 70,5\% по отношению к таковому в контрольной группе (табл. 1). При введении рчЛФ в дозах 100 мг/кг и 200 мг/кг уровень общего тестостерона приближался к контрольным величинам.

Поскольку главным предшественником всех стероидных гормонов является холестерин, было проанализировано влияние рчЛФ в дозах 20, 100 и 200 мг/кг на содержание общего холестерина в сыворотке крови крыс. При введении 100 мг/кг и 200 мг/кг уровень изучаемого показателя достоверно возрастал на $16,8 \%$ и $13,6 \%$ по сравнению с контрольной группой (табл. 2).

Долгое время считалось, что основная часть холестерина, которая используется в стероидогенезе, синтезируется из ацетата в стероидпродуцирующих клетках. Сейчас подавляющее большинство учёных полагает, что липопротеины плазмы, образование которых происходит в печени, являются одним из главных источников холестерина, задействованного в биосинтезе стероидных гормонов [25]. В связи с этим, мы проанализировали влияние рчЛФ на основные показатели липидного обмена сыворотки крови крыс. Было установлено, что в 3-ей и 4-ой группе исследуемых животных наблюдался статистически значимый рост уровня ХС ЛПНП (на 56,7\% и 37,9\% соответственно) по отношению к контрольной группе. Содержание ХС ЛПВП при воздействии рчЛФ в дозе 200 мг/кг достоверно увеличивалось на 16,2\%, а в дозах 20 и 100 мг/кг имело тенденцию к повышению на $13,2 \%$ и $21,3 \%$ соответственно. При дозах 100 мг/кг и 200 мг/кг наблюдалось значимое снижение уровня триглицеридов на $32,7 \%$ и $34,6 \%$ соответственно по сравнению с контролем. Уменьшение содержания анализируемого показателя вероятно связано со способностью тестостерона стимулировать гидролиз триглицеридов, непосредственно модулируя активность гормон-чувствительной липазы [26] и приводя к известному анаболическому эффекту тестостерона. Представленные результаты указывают на модуляцию лактоферрином липидного обмена и принципиально согласуются с серией работ японских ученых, в которых показано липолитическое действие бычьего ЛФ, а также его способность уменьшать количество висцерального жира и вызванную жирными кислотами липотоксичность (для обзора см. последнюю из серии публикаций [27]).

Таблица 1. Уровень общего тестостерона в гомогенате семенников крыс после 2,5 мес. перорального введения рекомбинантного лактоферрина человека (рчЛФ)

\begin{tabular}{|c|c|c|c|c|}
\hline \multirow{2}{*}{ Тестостерон, нмоль/л } & \multirow{2}{*}{ Контроль } & \multicolumn{3}{|c|}{ Концентрация рчЛФ } \\
\hline & & 20 мг/кг & 100 мГ/кГ & 200 мГ/кГ \\
\hline Семенники & $\begin{array}{c}44,00(37,50 ; 51,00) \\
(\mathrm{n}=7)\end{array}$ & $\begin{array}{c}75,00(59,00 ; 80,00) * \\
(\mathrm{n}=7)\end{array}$ & $\begin{array}{c}47,50(43,00 ; 55,00) \\
(\mathrm{n}=7)\end{array}$ & $\begin{array}{c}44,17(30,40 ; 55,00) \\
(\mathrm{n}=7)\end{array}$ \\
\hline
\end{tabular}

Примечание. Здесь и в таблице 2 * - достоверные отличия от контрольной группы (p<0,05), (Ме; 25\%-75\%).

Таблица 2. Уровень основных показателей липидного и белкового обмена в сыворотке крови крыс после 2,5 месяцев перорального введения рекомбинантного лактоферрина человека (рчЛФ)

\begin{tabular}{|c|c|c|c|c|}
\hline \multirow{2}{*}{ Показатели } & \multirow{2}{*}{ Контроль } & \multicolumn{3}{|c|}{ Концентрация рчЛФ } \\
\hline & & 20 мг/кг & 100 мг/кг & 200 мг/кГ \\
\hline $\begin{array}{c}\text { Общий холестерин, } \\
\text { (ммоль/л) }\end{array}$ & $\begin{array}{c}1,69(1,57 ; 1,84) \\
(\mathrm{n}=18)\end{array}$ & $\begin{array}{c}1,71(1,62 ; 1,92) \\
(\mathrm{n}=18)\end{array}$ & $\begin{array}{c}1,98(1,73 ; 2,08)^{*} \\
(\mathrm{n}=17)\end{array}$ & $\begin{array}{c}1,92(1,65 ; 2,08)^{*} \\
(\mathrm{n}=17)\end{array}$ \\
\hline $\begin{array}{l}\text { Триглицериды, } \\
\text { (ммоль/л) }\end{array}$ & $\begin{array}{c}2,12(1,65 ; 2,85) \\
(\mathrm{n}=18)\end{array}$ & $\begin{array}{c}1,96(1,77 ; 2,46) \\
(\mathrm{n}=18)\end{array}$ & $\begin{array}{c}1,42(1,27 ; 1,58)^{*} \\
(\mathrm{n}=18)\end{array}$ & $\begin{array}{c}1,38(1,31 ; 1,81)^{*} \\
(\mathrm{n}=18)\end{array}$ \\
\hline ХС ЛПНП, (ммоль/л) & $\begin{array}{c}0,73(0,60 ; 0,82) \\
(\mathrm{n}=14)\end{array}$ & $\begin{array}{c}0,60(0,48 ; 0,72) \\
(\mathrm{n}=18)\end{array}$ & $\begin{array}{c}1,15(0,79 ; 1,32) * \\
(\mathrm{n}=18)\end{array}$ & $\begin{array}{c}1,01(0,79 ; 1,39) * \\
(n=17)\end{array}$ \\
\hline ХС ЛПВП, (ммоль/л) & $\begin{array}{c}0,12(0,11 ; 0,14) \\
(\mathrm{n}=15)\end{array}$ & $\begin{array}{c}0,14(0,11 ; 0,17) \\
(\mathrm{n}=16)\end{array}$ & $\begin{array}{c}0,15(0,11 ; 0,17) \\
(\mathrm{n}=16)\end{array}$ & $\begin{array}{c}0,15(0,12 ; 0,20) * \\
(\mathrm{n}=15)\end{array}$ \\
\hline Альбумин, (г/л) & $\begin{array}{c}47,15(43,34 ; 54,54) \\
(\mathrm{n}=12)\end{array}$ & $\begin{array}{c}51,41(49,37 ; 55,75) \\
(\mathrm{n}=10)\end{array}$ & $\begin{array}{c}52,56(48,14 ; 62,61) * \\
(\mathrm{n}=13)\end{array}$ & $\begin{array}{c}58,19(54,69 ; 65,66) * \\
(\mathrm{n}=13)\end{array}$ \\
\hline Общий белок, (г/л) & $\begin{array}{c}83,08(77,85 ; 86,36) \\
(\mathrm{n}=18)\end{array}$ & $\begin{array}{c}82,76(77,85 ; 88,32) \\
(\mathrm{n}=18)\end{array}$ & $\begin{array}{c}82,43(75,89 ; 86,36) \\
(\mathrm{n}=18)\end{array}$ & $\begin{array}{c}83,74(81,12 ; 87,01) \\
(\mathrm{n}=18)\end{array}$ \\
\hline
\end{tabular}


Анализ влияния рчЛФ на основные показатели белкового обмена показал, что в 3-ей и 4-ой группе подопытных животных уровень альбумина в сыворотке крови достоверно повышался на 11,5\% и $23,4 \%$ соответственно. Вместе с тем, значимых различий в содержании общего белка между контрольной и опытными группами обнаружено не было, что согласуется с проведенными ранее исследованиями голландских учёных [28], в основу, которых был положен 13-ти недельный хронический эксперимент на крысах, потреблявших рчЛФ, полученный из молока трансгенных коров.

Зафиксированное увеличение уровня предшественников тестостерона в стероидогенезе и его главного субстрата - холестерина при действии рчЛФ свидетельствует о развитии метаболических сдвигов в стероидогенезе. Этот факт можно объяснить возможной способностью ЛФ ускорять процесс обновления билипидного слоя клеточных мембран, в состав которых входит холестерин, что косвенно подтверждается продемонстрированной активацией обмена липидов.

Вместе с тем, статистически значимый рост уровня свободного тестостерона и альбумина во всех экспериментальных группах может означать, что происходит увеличение доли именно биологически активного, связанного с альбумином и доступного для клеток-мишеней андрогена.

\section{ЗАКЛЮЧЕНИЕ}

Системное 2,5 месячное потребление экспериментальными животными per os рекомбинантного лактоферрина человека приводит к повышению уровня общего тестостерона в сыворотке крови и надосадочной жидкости гомогената семенников, коррелирующему с увеличением свободного тестостерона. При этом наблюдается возрастание концентрации субстратов стероидогенеза (холестерина, прогестерона и 17-ОН прогестерона) на фоне параллельного снижения содержания эстрадиола в сыворотке крови, что приводит к более чем трёхкратному повышению тестостерон/эстрадиолового индекса. Полученные результаты свидетельствуют об активации лактоферрином липидного обмена, синтеза андрогенов и создают теоретическую основу для использования изучаемого трансферрина в качестве корректирующего средства при профилактике гипогонадизма различной этиологии, с целью нормализации содержания эндогенного тестостерона и минимизации признаков андрогенного дефицита.

\section{ЛИТЕРАТУРА}

1. Collins L.L., Lee H.J., Chen Y.T., Chang M., Hsu H.Y., Yeh S., Chang C. (2003) Cytogenet. Genome Res., 103(3-4), 299-301.

2. Wang R.S., Yeh S., Tzeng C.R., Chang C. (2009) Endocr. Rev., 30(2), 119-132.

3. Huhtaniemi I., Pelliniemi L.J. (1992) Proc. Soc. Exp. Biol. Med., 201(2), 125-140.
4. Awoniyi C.A., Santulli R., Sprando R.L., Ewing L.L., Zirkin B.R. (1989) Endocrinology, 124(3), 1217-1223.

5. Wilson J.D. (2001) J. Am. Med. Assoc., 285(5), 624-627.

6. Zaidi S.K., Wen-Jun Shen, Azhar S. (2012) Open Longevity Science, 6, 1-30.

7. Jayaraman A., Lent-Schochet D., Pike C.J. (2014) J. Neuroinflammation, 11, 162.

8. Диатроптов М.Е., Диатроптова М.А., Кондашевская М.В. (2012) Фундаментальные исследования, 9, 273-277.

9. Ахмерова Л.Г. (2006) Успехи физиологических наук, 37(1), 28-36.

10. Ye L., Su Z.J., Ge R.S. (2011) Molecules, 16(12), 9983-10001.

11. Kostic T.S., Stojkov N.J., Bjelic M.M., Mihajlovic A.I., Janjic M.M., Andric S.A. (2011) Toxicol. Sci., 121(2), 397-407.

12. Ge R.S., Hardy M.P. (2007) In The Leydig Cell in Health and Disease (Payne A.H., Hardy M.P., eds.) Humana Press, New York, pp. 55-70.

13. Payne A.H., Youngblood G.L. (1995) Biol. Reprod., 52(2), 217-225.

14. Carruthers M. (1996) The Male Menopause: Restoring Vitality and Virility, Harpers Collins Publishing, London, pp. 132.

15. Goldman I.L., Georgieva S.G., Gurskiy Ya.G., Krasnov A.N., Deykin A.V., Popov A.N., Ermolkevich T.G., Budzevich A.I., Chernousov A.D., Sadchikova E.R. (2012) Biochemistry Cell Biology, 90(3), 513-519.

16. Chekhun V.F., Zalutskii I.V., Naleskina L.A., Lukianova N.Yu., Yalovenko T.M., Borikun T.V., Sobchenko S.O., Semak I.V., Lukashevich V.S. (2015) Experimental Oncology, 37(3), 181-186.

17. Лукашевич В.С., Будевич А.И., Семак И.В., Кузнецова В.Н., Малюшкова Е.В., Пыж А.Э., Новаковская С.А., Рудниченко Ю.А., Попков Н.А., Ивашкевич О.А., Залуикий И.В. (2016) Доклады НАН Беларуси, 60 (1), 72-81.

18. Sharma S., Sinha M., Kaushik S., Kaur P., Singh T.P. (2013) Biochem. Res. Int., 2013, 1-8.

19. Sreedhara A., Flengsrud R., Prakash V., Krowarsch D., Langsrud T., Kaul P., Devold T.G., Vegarud G.E. (2010) Int. Dairy J., 20, 487-494.

20. García-Montoya I.A., Siqueiros-Cendón T., Arévalo-Gallegos S., Rascón-Cruz Q. (2012) Biochim. Biophys. Acta., 3, 226-236.

21. Tang L., Cui T., Wu J.J., Liu-Mares W., Huang N., Li J. (2010) Wound Repair Regen., 18(1), 123-131.

22. Kanwar J.R., Roy K., Patel Y., Zhou S.F., Singh M.R., Singh D., Nasir M., Sehgal R., Sehgal A., Singh R.S., Garg S., Kanwar R.K. (2015) Molecules. 20(6), 9703-9731.

23. Рудниченко Ю.А. (2015) Весці НАН Беларусі. Сер. мед. навук., 2, 102-105.

24. Khan S., Telangband A.G., Malik J.K. (2013) Wudpecker Journal of Pharmacy and Pharmocology, 2(3), 033-048.

25. Azhar S., Reaven E. (2002) Mol. Cell Endocrinol., 195, 1-26.

26. Langfort J., Jagsz S., Dobrzyn P., Brzezinska Z., Klapcinska B., Galbo H., Gorski J. (2010) Biochem. Biophys. Res. Commun., 399(4), 670-676.

27. Morishita S., Tomita K., Ono T., Murakoshi M., Saito K., Sugiyama K., Nishino H., Kato H. (2015) Biochemistry Cell Biology, 93(6), 566-573.

28. Appel M.J., van Veen H.A., Vietsch H., Salaheddine M., Nuijens J.H., Ziere B., de Loos F. (2006) Food Chemical Toxicology, 44(7), 964-973.

Поступила: $\quad$ 22. 01. 2016. Принята к печати: 29. 09. 2016. 


\title{
EXPERIMENTAL STUDY OF THE INFLUENCE OF RECOMBINANT HUMAN LACTOFERRIN ON THE LEVELS OF ANDROGENS AND BASIC PARAMETERS OF LIPID AND PROTEIN METABOLISM
}

\section{Ju.A. Rudnichenko, V.S. Lukashevich, I.V. Zalutsky}

Institute of Physiology, National Academy of Sciences of Belarus, 28 Akademycheskaya str., Minsk, 220072 Belarus; e-mail: link060619@list.ru

\begin{abstract}
System administration of human recombinant lactoferrin per os to rats for 2,5 months increased serum and testicular levels of total testosterone. The data correlated with the increase in free testosterone levels. These changes were accompanied by an increase of concentrations of steroidogenesis substrates (cholesterol, progesterone, and 17-OH progesterone) and a decrease of the estradiol content in blood serum. This resulted in the 3.6-3.8-fold increase of the testosterone/estradiol index. Basic parameters of lipid and protein were also studied. Results of this study suggest that lactoferrin administration causes activation of androgen synthesis and lipid metabolism.
\end{abstract}

Key words: testosterone, steroidogenesis, recombinant human lactoferrin, lipid and protein metabolism 